International Journal of Linguistics, Literature and Translation

ISSN: 2617-0299 (Online); ISSN: 2708-0099 (Print)

DOI: $10.32996 / \mathrm{ijlt}$

Journal Homepage: www.al-kindipublisher.com/index.php/ijllt

\title{
The Effect of Language of Instruction on Middle School Students' Achievement, Academic Self-concept and Comprehension Abilities in Science Learning
}

\author{
Abdelaziz OUCHAIB 8 (D) \\ PhD Student, Department of English, Faculty of Arts and Human Sciences, Moulay Ismail University, Meknes, Morocco \\ $\triangle$ Corresponding Author: Abdelaziz OUCHAIB, E-mail: abdelaziz.ouchaib@yahoo.com/a.ouchaib@edu.umi.ac.ma
}

\section{ARTICLE INFORMATION}

Received: March 08, 2021

Accepted: April 14, 2021

Volume: 4

Issue: 4

DOI: 10.32996/ijllt.2021.4.4.14

\section{KEYWORDS}

Science education, medium of instruction, science achievement, science academic self-concept, comprehension abilities, language planning and policy

\section{ABSTRACT}

Starting from 2019, Morocco has implemented a new language policy on the medium of instruction for science education. This policy stipulates that scientific and technical subjects should be taught in French. Research has unveiled numerous problems regarding the adoption of foreign or second languages as mediums of instruction .This being the case; the purpose of this study is to investigate the effect of language of instruction on the quality of science education. The researcher deployed an explanatory sequential design. Research instruments consisted of a Likert-scale questionnaire distributed among 114 9th grade middle school students, classroom observations, and interviews with science instructors. The results revealed that the French-medium participants are disadvantaged in learning scientific subjects as they showed lower achievement scores, lower levels of academic self-concept, and they relatively encountered more difficulties with the comprehension of scientific courses. By conclusion, this paper provides a number of pedagogical implications addressed to middle school students, middle school science teachers, school counselors, and finally to language policy decision-makers.

\section{Introduction}

The language of instruction (LOI) in the Moroccan educational system has always been a major topic of concern since the country gained independence in 1956 after 44 years as a French protectorate. This controversy intensified recently when the government passed a new law that stipulates the use of French as the LOI of scientific and technical subjects in middle schools, in the first phase of the framework law of education reform, and then gradually generalize this language policy to secondary schools. The goal behind this new policy, according to the Minister of education, is to bridge the linguistic gap between tertiary education and secondary schools regarding the medium of instruction in science education.

Moroccan academics and politicians are split over the adequacy of this new science education policy. As for politicians, the House of Representatives passed the draft law; 241 Members of Parliament voted in favor, but only four members voted against it, whereas 21 members from the Independence Party abstained. Conversely, many scholars and academics uphold that education and politics should be separate. Benmamoun (2001, p.95) contends that "the language policy of the country is driven by religion, ethnicity and issues of identity". As a matter of fact, this policy jeopardizes the quality of education since it does not consider what research tells about the relationship between language policy and education quality. In other terms, the country's language policy is illuminated by the decisions of politicians rather than by recommendations of scientific research.

Given this state of affairs, this paper investigates the impact of the language of instruction on the teaching-learning process of scientific subjects, namely math, physics and natural sciences. Obviously, the results allow the researcher to draw conclusions about students' academic self-concept, comprehension abilities, achievement and motivation in learning scientific subjects. Along these lines, this study seems to have constructive pedagogical implications for educational stakeholders including middle school students, middle school science teachers, school counsellors and language policy decision-makers.

K C AL-KINDI CENTER

$\mathbf{R}$ D FOR RESEARCH AND DEVELOPMENT

Your gateway to world-class research

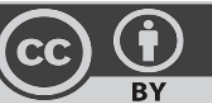

Published by Al-Kindi Center for Research and Development, London, United Kingdom. Copyright (c) the author(s). This open access article is distributed under a Creative Commons Attribution (CC-BY) 4.0 license 


\section{Literature Review}

A growing body of literature has investigated the relationship between LOI and learning outcomes. In recent years, there has been considerable interest in its effect on the quality of science education. A plethora of international research reported relationship between LOI and achievement in science. However, at the local level, research has tended to focus on science learning in tertiary education rather than in secondary education. All the local studies that could be found on this issue approached it in higher education (Belhiah \& Abilkassem, 2016; Enajji, 1991; EL Allam \& Laaraj, 2016; Belhassan, 2017) and no studies were conducted on LOI and science education in middle schools. Thereupon, this research comes to fill the gap because this topic is still poorly understood among local researchers.

On the theoretical side, most researchers have emphasized the relationship between LOI and achievement in scientific courses. They argue that using a foreign language for the instruction of scientific and technical subjects may give rise to conceptual, linguistic or psychological problems for both learners and teachers.

Regarding conceptual problems, Gudula (2017) maintains that "a child with a language disorder may not have the basic abilities required to complete mathematical problems, equations, and formulae" (p.23). He extends his argument by saying that "Learners are faced with the burden of thinking answers in their own language and then translate them into the language of instruction" (ibid, pp. 23-24). By the same token, Howie (2003, cited in Gudula, 2017) believes that:

The most significant factor in learning Science and Mathematics is not whether the learners are rich or poor. It is whether they are fluent in English (SL). While there is surely some truth to the view that weak language proficiency in English (SL) spills over to learning in other subject areas (scientific courses). (p.26)

As for the linguistic difficulties, the mastery of the LOI is indispensable in science education to the extent that Ellsworth (2013, p.13) asserts that "language barriers can have long-term effects on learners' academic performance". Henderson \& wellington $(1998$, p.35) add that "for many pupils the greatest barrier to learning science is the language barrier". Another argument for the importance of the mastery of language in science education appeared in Merino \& Scarcella (2005). They stated that "in order to learn science, students need to master the academic literacy skills specific to that discipline" (p.23). Along the same line, Stoffelsma \& Spooren (2019) conducted a longitudinal study on the relationship between English reading proficiency and academic achievement of first-year science and mathematics students. The results of their study showed that language proficiency is important for academic achievement. Equally important, Tina \& Wai (2007) assert that the major reason why language is a barrier in science education is because "scientific terms, whether technical or non-technical, are unique in nature and they are seldom used in other contexts" (p.48). They continue explaining this barrier saying that "students have to learn a new language at the same time; they are required to acquire a new subject matter" (ibid, p.48).

Additionally, the ability to communicate and arrive at conclusions through getting involved in scientific debates is also of paramount importance. According to the American national council (1996) cited in Sadler (2006) science literacy involves students' ability to "engage intelligently in public discourse and debate" (p.13) and the ability to "conduct explanations of natural phenomena, test these explanations in many different ways and communicate their ideas to others" (ibid, p.20). Therefore, starting scientific debates and explaining scientific phenomena would not be within the reach of students if they are not equipped with language proficiency.

Concerning the psychological barriers LOI can raise, research proved the existence of a relationship between the LOI for scientific subjects and students' levels of motivation and self-efficacy. Rahman, et al. (2010) conducted a study on the effect of LOI on Malaysian students' motivation and self-efficacy. They found that the students who were taught in their native language were more motivated, and they scored better than the ones taught in English. Equally important, Mkimbili, et al. (2019) found that the major challenge to Tanzanian students' motivation for science was their insufficient competence in the language of instruction.

On the practical side, there has been a great deal of arguments on the effect of LOI on achievement in learning science. Evelian, et al. (2014), for example, investigated this issue in Belgium. They found that the students who were taught science in a language other than their mother tongue experienced difficulties with scientific subjects. Similarly, Sabri, et al. (2005) conducted a causalcomparative study with the aim to determine the differences between the students who took the science courses in their native language (Turkish) and the ones who took science courses in a foreign language (English). The results revealed that the students who were taught in English had more misconceptions than the ones who were taught in Turkish.

No less significant, in 2007, Vuyokazi conducted a co-relational study investigating the effect of isiXhora (a native language in South Africa), on the one hand, and English (a foreign language), on the other hand, on students' academic achievement in science. He found that there exists a positive correlation between the use of students' mother tongue and their academic achievement. In this respect, he shares with Wallace, et al. (2007, p.33) the view that: "the use of everyday words and concepts enables learners to explore and clarify the meaning of technical terms or new concepts". In addition, Albakri (2017), in a study on 
the implementation of English as a medium of instruction in Oman, revealed that her participants faced great difficulties in their scientific studies mainly because of their insufficient foreign language proficiency.

Studies also show that science instructors object to the use of second and foreign languages as mediums of instruction for scientific subjects. Kilikaya (2006) and Kirkgoz (2005) found that Turkish educators opposed the use of English as a medium of instruction because it detracted from students' abilities to understand concepts, and it made the study of scientific subjects excessively time-consuming because of the amount of translation they have to do. Similarly, Vizcondes (2006) reported that teachers in the republic of Philippines prefer to teach science through Filipino although English is the official medium of instruction; they argued that students understand the lessons only when taught in Filipino. In Sri Lanca, Wijayatunga (2018) found that the majority of teachers are not proficient in the medium of instruction (English). In Lebanon, Mirza (2015) examined the attitudes of math and science student-teachers towards using English as a medium of instruction. Her study revealed that teachers had to code switch from English to Arabic to ensure comprehension.

Generally, then, a large number of researchers share the belief that the medium of instruction for scientific and technical subjects affects students' achievement, their academic self-concept and their comprehension abilities in science learning. Researchers have also distinguished three areas of influence: the comprehension of lessons, the psychology and attitudes of the learners, and their linguistic proficiency.

\section{Methodology}

\subsection{Research Questions}

This study is meant to address the following questions:

- Does the LOI affect students' achievement in scientific subjects, namely math, physics and natural sciences in Moroccan middle schools?

- Does the LOI affect middle school students' academic self-concept and their comprehension abilities in learning scientific subjects?

- Does the LOI affect science teachers' instructional performance in teaching scientific subjects?

\subsection{Participants}

The present study limits the population it seeks to investigate to the $9^{\text {th }}$ grade students in Moroccan middle schools and their teachers of scientific subjects. Moroccan middle school students at this level are divided among two major specialties depending on the LOI, namely French-medium of instruction students (FMI) and Arabic-medium of instruction students (AMI). Therefore, a total of 114 students were non-randomly selected, and they were distributed in regards to their gender and specialties as shown in Table 1.

Table 1: The distribution of the participants according to gender and LOI variables $(n=114)$

\begin{tabular}{|c|c|c|c|c|}
\hline \multirow{2}{*}{ Institution } & \multicolumn{2}{|c|}{ Gender } & \multicolumn{2}{c|}{ Specialty } \\
\cline { 2 - 5 } & Male & Female & AMI & FMI \\
\hline Jabir Ibno Hayan & 54 & 60 & 65 & 49 \\
\hline Total & \multicolumn{3}{|c|}{114} \\
\hline
\end{tabular}

\subsection{Research Instruments}

\subsubsection{The students' Grades}

To investigate the extent to which the LOI affects students' achievement in science learning, this study made a comparison between the performances of the participants in scientific subjects based on their grades in the first term report cards. To this end, independent $\mathrm{t}$-test was used to determine whether there exist statistically significant differences between the grades of FMI students and those of their AMI counterparts.

\subsubsection{The students' Questionnaires}

In order to examine the effect of the LOI on students' academic self-concept and on their comprehension abilities in scientific subjects, a Liker scale questionnaire was designed. It was formulated in accordance with the research questions of this study. In fact, it was made up of three parts containing seventeen closed-ended questions. The first part included two questions designed to obtain demographic information on the participants including their gender and their LOI. The second part consisted of eight questions measuring the effect of the LOI on students' academic self-concept. The third part included seven questions examining the effect of LOI on participants' comprehension abilities of scientific subjects. Most of the items in the questionnaire were adapted from previous studies (You, 2018; Yip, 2006; Wenglinsky, 1996). The questionnaire's reliability was tested for internal consistency of the scales using the Cronbach alpha test. The results are shown in the table below: 
Table 2: The alpha reliability of scales

\begin{tabular}{ll}
\hline Scales & Cronbach alpha \\
\hline the effect of LOI on participants' self-concept (8 items) & .753 \\
\hline the effect of LOI on participants' comprehension abilities (7 items) & .738 \\
\hline
\end{tabular}

\subsubsection{Non-participatory classroom observation}

This instrument was used to understand the details of the problem under investigation through getting an inside view of reality in the classroom. Following this background, a classroom observation grid was developed and used for two reasons. Firstly, it enabled the researcher to make in-depth analysis of the research problem by virtue of having direct contact with teachers' and students' behaviours during the sessions. Secondly, direct observations could compensate for any potential bias in the participants' responses, and it increased the precision of the results of this study by providing a chance to check the accuracy of the data supplied by the participants in the questionnaires.

\subsubsection{Interviews}

Six semi-structured interviews with the teachers of the three scientific subjects to the students who responded to the questionnaire were used in this study to offer explanation to the quantitative findings. The focus of the open-ended questions in the interviews was on teachers' perceptions towards the effects of LOI on their instructional performance.

\section{Results}

\subsection{Findings from the quantitative data}

\subsubsection{Students' science achievement by the language of instruction}

In connection with the first research question, independent samples t-test was conducted to compare the mean grades of the participants according to their LOI. The aim was to see which LOI brings about better results. The table below displays descriptive statistics for the two groups:

Table 3: Descriptive statistics from independent t-test on samples of FMI and AMI participants

\begin{tabular}{|cc|c|c|c|c|}
\hline \multicolumn{2}{|c|}{ Language of instruction } & $\mathrm{N}$ & Mean & Std. Deviation & Std. Error Mean \\
\hline \multirow{2}{*}{ Science Mean } & 49 & 10,9722 & 2,92923 &, 41846 \\
\cline { 2 - 6 } & FMI & 65 & 12,7059 & 3,18376 &, 39490 \\
\hline
\end{tabular}

According to Table 3, there is a significant difference between the means of the two groups. It seems that AMI participants $(\mathrm{N}=65)$ outperformed their $\mathrm{FMI}$ counterparts with a statistically higher score $\mathrm{M}=12.7059(\mathrm{SD}=3.18)$. By comparison, the FMI participants ( $N=49)$ scored lower with $M=10.9722(S D=2.92)$. The mean difference between the two groups is $(-1.73370)$. The SD of the FMI group shows that grades of students are less dispersed around the mean compared to the AMI groups whose grades are more dispersed.

As has been observed in Table 3, there seems to be a difference between the two groups in terms of dispersion of the scores. AMI group scored higher than their FMI peers, which can be better visualized and further explained with a boxplot.

Figure 1: Boxplot for the overall students' means in scientific subjects

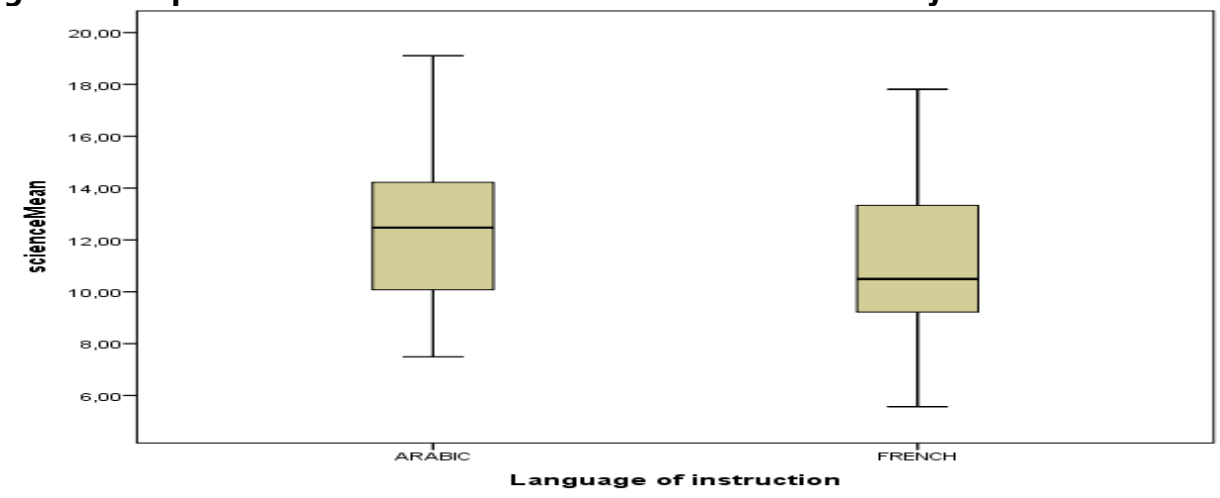

This boxplot clearly shows the distribution of the scores of the two groups. Data values of FMI respondents range from 5.57 to 17.81 (range $=12.47$ ). $50 \%$ of their scores are lower than 10.49 . Additionally, the distribution of their scores is symmetric because the whiskers are about the same on both sides of the box. By comparison, the scores of the AMI groups range from 7.49 to $19.11 .50 \%$ of them are higher than 12.47 . Their distribution is positively skewed. In general, the students who use Arabic as 
their LOI are more likely to score higher in scientific subjects than the students who are taught in French. As a matter of fact, only $25 \%$ of the AMI participants scored below average while almost $50 \%$ of the FMI sample scored less than 10 .

\subsubsection{Students' science academic self-concept by language of instruction}

It is hypothesized that LOI affects Moroccan middle school students' academic self-concept. With a view to test this hypothesis, the table below provides an overview of students' academic self-concept levels.

Table 4: Results for students' academic self-concept by language of instruction

\begin{tabular}{|c|c|c|c|c|c|c|c|c|c|c|}
\hline \multirow{3}{*}{$\begin{array}{l}\text { Academic Self- } \\
\text { concept items in the } \\
\text { survey }\end{array}$} & \multicolumn{10}{|c|}{ Language of instruction } \\
\hline & \multicolumn{5}{|c|}{ FRENCH } & \multicolumn{5}{|c|}{ ARABIC } \\
\hline & $\begin{array}{l}S D \\
\%\end{array}$ & $\begin{array}{l}D \\
\%\end{array}$ & $\begin{array}{l}N \\
\%\end{array}$ & $\begin{array}{l}A \\
\%\end{array}$ & $\begin{array}{c}S A \\
\%\end{array}$ & $\begin{array}{c}S D \\
\%\end{array}$ & $\begin{array}{l}D \\
\%\end{array}$ & $\begin{array}{l}N \\
\%\end{array}$ & $\begin{array}{l}A \\
\%\end{array}$ & $\begin{array}{l}S A \\
\%\end{array}$ \\
\hline $\begin{array}{l}\text { My achievement in } \\
\text { scientific subjects is } \\
\text { better than that in } \\
\text { other subjects. }\end{array}$ & 0,0 & 38,8 & 24,5 & 36,7 & 0 & 0,0 & 0,0 & 18,5 & 61,5 & 20,0 \\
\hline $\begin{array}{l}\text { My performance in } \\
\text { scientific subjects is } \\
\text { always good. }\end{array}$ & 8,2 & 44,9 & 16,3 & 30,6 & 0 & 0,0 & 7,7 & 15,4 & 61,5 & 15,4 \\
\hline $\begin{array}{l}\text { I believe I can get the } \\
\text { best grade in science. }\end{array}$ & 20,4 & 26,5 & 12,2 & 40,8 & 0 & 0,0 & 0,0 & 12,3 & 69,2 & 18,5 \\
\hline $\begin{array}{l}\text { I am confident I will do } \\
\text { well in science tests. }\end{array}$ & 10,2 & 30,6 & 20,4 & 38,8 & 0 & 0,0 & 9,2 & 0,0 & 76,9 & 13,8 \\
\hline $\begin{array}{l}\text { I have the ability to } \\
\text { continue my future } \\
\text { science studies in } \\
\text { science streams in high } \\
\text { school and in the } \\
\text { university. }\end{array}$ & 16,3 & 28,6 & 32,7 & 22,4 & 0 & 1,5 & 7,7 & 15,4 & 44,6 & 30,8 \\
\hline $\begin{array}{l}\text { I am satisfied with my } \\
\text { performance in } \\
\text { scientific subjects. }\end{array}$ & 14,3 & 42,9 & 16,3 & 26,5 & 0 & 0,0 & 7,7 & 3,1 & 67,7 & 21,5 \\
\hline $\begin{array}{l}\text { I can myself solve } \\
\text { exercises of the } \\
\text { scientific subjects and } \\
\text { I'm not worried about } \\
\text { tests. }\end{array}$ & 12,2 & 36,7 & 24,5 & 26,5 & 0 & 0,0 & 3,1 & 12,3 & 64,6 & 20,0 \\
\hline $\begin{array}{l}\text { While sitting for tests } \\
\text { in scientific subjects, I } \\
\text { am able to answer all } \\
\text { questions. }\end{array}$ & 4,1 & 42,9 & 20,4 & 32,7 & 0 & 0,0 & 3,1 & 18,5 & 72,3 & 6,2 \\
\hline
\end{tabular}

The frequencies show significant and consistent dissimilarities between the two groups, which suggests that the LOI affects their levels of academic self-concept. It appears that the students studying scientific subjects in French have substantially less esteem regarding their academic self-concept in science learning than their counterparts who study science in Arabic. As shown in the table, AMI students reported that they were more confident and satisfied with their achievement in scientific subjects. They also claimed the ability to continue their science studies and get good grades in their future secondary and tertiary science education.

By way of illustration, most of the AMI students (81.5\%) agreed or strongly agreed that their achievement in scientific subjects is better than their achievement in the other school subjects compared to $36.7 \%$ of their FMI counterparts. Equally significant, $90.7 \%$ of AMI students stated that they were confident to do well in science tests in contrast to only $38.8 \%$ of FMl students. Similarly, $89.2 \%$ of the students who learn science in Arabic indicated that they were satisfied with their performance whereas only $26.5 \%$ of the $\mathrm{FMI}$ students said so. Finally, $84.6 \%$ of AMI group declared their ability to solve science exercises by themselves and not being worried about tests compared to only $26.5 \%$ of FMI students. 
Accordingly, the AMI participants showed a higher academic self-concept in science learning than their FMI peers. However, one cannot attribute these differences to LOI without conducting an association test. Therefore, the total of the items which measure students' academic self-concept was computed as an additional independent variable to test the relationship between participants' responses and the language through which they learn scientific subjects. Table 5 displays the results:

Table 5: Test of independence between LOI and students' academic self-concept

\begin{tabular}{|l|r|r|r|}
\hline & \multicolumn{1}{|c|}{ Value } & df & \multicolumn{1}{|c|}{ Asymp. Sig. (2-sided) } \\
\hline Pearson Chi-Square & $42,535^{\mathrm{a}}$ & 27 &, 029 \\
Likelihood Ratio & 54,616 & 27 &, 001 \\
N of Valid Cases & 114 & & \\
\hline
\end{tabular}

The results reveal that there is a statistically significant relationship between the two variables (chi square value $=42,535 \mathrm{a}, \mathrm{df}=$ $27, p<0,05)$. A significantly larger portion of AMI students (75.4\%) reported that they are able to continue their future science studies in science streams in high school and in the university compared to only $22.4 \%$ of FMI students. $90.7 \%$ of AMI respondents reported that they are confident of doing well in science tests, whereas only $38.8 \%$ of FMl participants said so (see Table 4).

\subsubsection{Students' comprehension abilities in science learning by language of instruction}

In the students' questionnaire, items 9-15 measured the participants' comprehension abilities in learning scientific subjects. Table 6 below displays the responses of students regarding this variable. It shows significant differences between students' comprehension abilities according to their LOI. Apparently, AMI students possess stronger comprehension abilities in scientific subjects than their FMI peers.

Table 6: Results for students' comprehension abilities by the language of instruction

\begin{tabular}{|c|c|c|c|c|c|c|c|c|c|c|}
\hline \multirow{4}{*}{$\begin{array}{l}\text { Comprehension ability items in the } \\
\text { survey }\end{array}$} & \multicolumn{10}{|c|}{ Language of instruction } \\
\hline & \multicolumn{5}{|c|}{ FRENCH } & \multicolumn{5}{|c|}{ ARABIC } \\
\hline & $S D$ & $D$ & $N$ & $A$ & $S A$ & $S D$ & $D$ & $N$ & $A$ & $S A$ \\
\hline & $\%$ & $\%$ & $\%$ & $\%$ & $\%$ & $\%$ & $\%$ & $\%$ & $\%$ & $\%$ \\
\hline $\begin{array}{l}\text { The LOI doesn't increase the difficulty } \\
\text { of scientific subjects. }\end{array}$ & 2,0 & 69,0 & 16,3 & 12,6 & 0,0 & 0,0 & 10,8 & 1,5 & 86,2 & 1,5 \\
\hline $\begin{array}{l}\text { The scientific subjects are easy to } \\
\text { understand. }\end{array}$ & 22,4 & 40,8 & 14,3 & 22,4 & 0,0 & 0,0 & 4,6 & 24,6 & 55,4 & 15,4 \\
\hline $\begin{array}{l}\text { I understand the explanations of my } \\
\text { science teachers thanks to LOI. }\end{array}$ & 22,4 & 42,9 & 0,0 & 32,7 & 2,0 & 0,0 & 9,2 & 3,1 & 69,2 & 18,5 \\
\hline $\begin{array}{l}\text { Sometimes I ask my science teachers } \\
\text { questions related to language } \\
\text { comprehensibility. }\end{array}$ & 38,8 & 12,2 & 6,1 & 42,9 & 0,0 & 4,6 & 46,2 & 15,4 & 32,3 & 1,5 \\
\hline $\begin{array}{l}\text { Sometimes, I do not answer correctly } \\
\text { because I do not understand the } \\
\text { question. }\end{array}$ & 0,0 & 32,7 & 10,2 & 53,1 & 4,1 & 24,6 & 41,5 & 7,7 & 26,2 & 0,0 \\
\hline $\begin{array}{l}\text { Overall I am very happy with my } \\
\text { science achievement. }\end{array}$ & 22,4 & 55,1 & 8,2 & 14,3 & 0,0 & 3,1 & 6,2 & 6,2 & 67,7 & 16,9 \\
\hline $\begin{array}{l}\text { I think I need to attend private lessons } \\
\text { in scientific subjects. }\end{array}$ & 0,0 & 6,1 & 16,3 & 63,3 & 14,3 & 15,4 & 33,8 & 30,8 & 20,0 & 0,0 \\
\hline
\end{tabular}

As shown above, $87.7 \%$ of AMI agreed or strongly agreed that using Arabic as a LOI does not increase the difficulty of scientific subjects while, surprisingly, the most remarkable result to emerge from the data is that $71 \%$ of the FMI students reported that French increases the difficulty of science learning. Similarly, item 2 reinforces the findings from item one. $63.2 \%$ of FMI students reported that it is not easy to understand scientific subjects, whereas $70.8 \%$ of their AMI peers indicated that scientific subjects are easy to understand. No less important, only $34.7 \%$ of FMI participants stated that they could understand the explanation of their science teachers, $42.9 \%$ of them said that they ask their teachers questions related to language comprehensibility and $77.6 \%$ declared that they need to attend private lessons in scientific subjects. In contrast, $87.7 \%$ of AMI students stated that they can understand the explanation of science teachers, $33.8 \%$ of them ask questions related to language comprehensibility, and only $20 \%$ reported that they need to attend private lessons. 
Accordingly, it seems that LOI has a significant effect on students' comprehension abilities in science learning. AMI participants showed higher comprehension abilities in comparison to FMI participants. However, to confirm that this finding is not attributed to chance or arbitrariness, it requires conducting a chi square test of association.

Table 7: Test of independence between LOI and students' comprehension abilities

\begin{tabular}{|l|r|r|r|}
\hline & \multicolumn{1}{|c|}{ Value } & df & Asymp. Sig. (2-sided) \\
\hline Pearson Chi-Square & $26,000^{\mathrm{a}}$ & 13 &, 017 \\
Likelihood Ratio & 34,800 & 13 &, 001 \\
N of Valid Cases & 114 & & \\
\hline
\end{tabular}

The results indicate that there is a statistically significant relationship between the two variables (chi square value $=26,000^{\mathrm{a}}$, $\mathrm{df}=$ $13, p<0,05)$. A significantly larger portion of FMI students (77.6\%) reported that they need to attend private lessons in scientific subjects compared with only $20 \%$ of AMI students. Similarly, $71 \%$ of them agreed that LOI increases the difficulty of scientific subjects (see Table 6).

\subsubsection{Findings from Classroom observations}

With the aim to further investigate the research questions of this study, classroom observations were conducted on a total number of six lessons given by three teachers. The three teachers were observed six times giving three science lessons in Arabic and then the same lessons in French. Based on the frequencies of occurrence of these classroom practices, it appears that highly significant dissimilarities exist between FMI groups and their AMI peers. The following figure displays the results of observations:

Figure 2: Frequency of occurrence of classroom practices by LOI

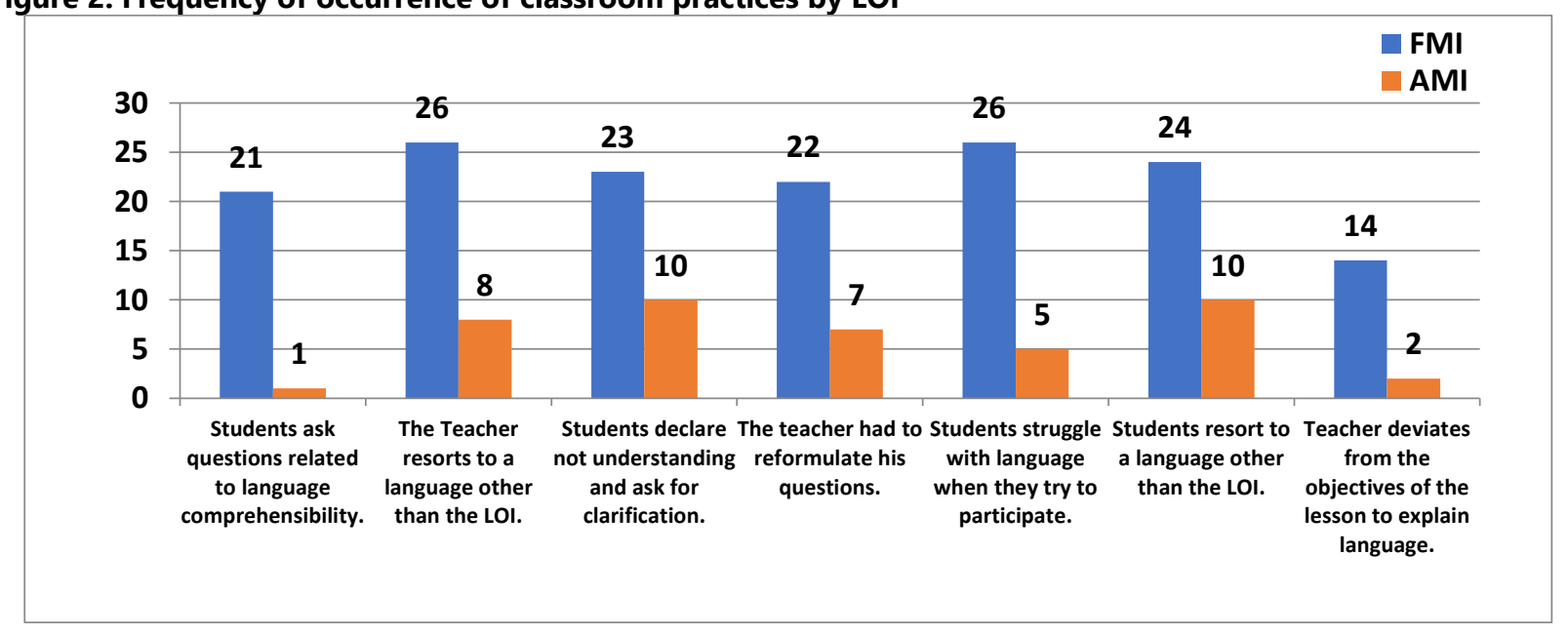

As shown in figure 2, some major differences can be noticed regarding classroom practices and the LOI. For example, a huge gap is noticed in the frequencies of students asking questions related to language comprehensibility (21 times in FMl groups compared to only once in AMI groups). Equally significant, FMI teachers resorted to a language other than the LOI 26 times compared to 8 times by AMI teachers. Similarly, FMI students resorted to another language 24 times compared to 10 times by LOI students. However, the commonality between them is resorting to the same alternative language: Moroccan Arabic.

The differences between the two groups are also apparent for the $5^{\text {th }}$ item in the grid. Students' struggle with language when they participate was more frequent in FMI classes; it occurred 26 times in FMI classes compared to 5 times in the AMI ones. No less important, teachers in FMI classes deviated from the objectives of their lessons to explain language 14 times whereas this classroom practice occurred only twice in AMI classes.

\subsection{Findings from the qualitative data}

\subsubsection{Findings from the Interviews}

In connection with the third research question, this section presents the results from the qualitative data collected through semistructured interviews with six science teachers of the students who responded to the questionnaire. The aim behind the use of this data collection instrument, as stated in the methodology section, is to explain and elaborate on information obtained from students' questionnaires and classroom observations. 
The demographics of the interviews can be summarized as follows: two of the interviewees were male and one was female. All of them teach in middle school. However, they are of different professional qualifications and they hold different academic degrees. Two of them are CPR graduates holding BA degrees, and the third is an ENS graduate and a PhD holder. They teach different scientific subjects which are math, physics and natural sciences. The answers provided by the interviewees were translated, transcribed and analyzed.

\section{Teachers' responses to the first question}

In answering the first question which reads "Which language of instruction makes you confident of your teaching? Why?" .All interviewees reported that teaching scientific subjects in Arabic is more appropriate. Among the reasons why they chose Arabic is that it enables them to teach more efficiently because their students find it easier to understand the lessons making less efforts, and they do not have to translate language. Moreover, they stated that Arabic promotes communication in the classroom; that is, Students can communicate more effectively with instructors in Arabic than in French. The interviewees also mentioned that teaching in Arabic helps them to attain the objectives of their lesson plans more quickly and more easily.

On the other hand, teachers stressed that teaching scientific subjects in French makes students depend more on rote learning and memorizing French terms because of their low proficiency in French. Therefore, students have to do two tasks concurrently, learning language and learning content; which results in students not gaining a deep understanding of scientific subjects. Moreover, the interviewees mentioned that teaching in French is extremely tiring and time consuming. They devote much time to translation and to the repetition of their explanations because they have to teach content and language simultaneously.

\section{Teachers' responses to the second question}

This question reads "do you think your pre-service training qualifies you to teach science both in Arabic and in French? Explain?"Five of The interviewed teachers noted that the pre-service training they received was in Arabic. After the implementation of the framework law of education, they received a few hours of training on how to teach scientific subjects in French. However, they admitted that they are not professionally qualified to teach in French. The third interviewee, a math teacher, reported that although the pre-service training was in Arabic, the LOI at university was French. And as his subject is technical in nature; and does not involve much discourse, he finds it easy to teach in both languages.

\section{Teachers' responses to the third question}

There is considerable congruity between interviewees' answers to the third question: "How do you describe your experience with teaching science in French?" three teachers out of five reported that teaching scientific subjects in French is a tiring and frustrating experience. "I have to re-explain in Arabic everything I explain in French" said a physics instructor. The two natural sciences teacher mentioned that they have to redouble their efforts teaching both language and science because of the low proficiency of students in French. They hope the ministry of education goes back to the old system stipulating Arabic as the only LOI. The third interviewee appears to be more positive admitting the difficulty of teaching in French; however, he considers this experience a challenge for him to improve his instructional competence and to grow professionally.

\section{Teachers' responses to the fourth question}

In agreement with their answers to the question "how do you describe your experience with teaching science in Arabic? The interviewees seem more enthusiastic for using Arabic to teach their subjects. Two instructors reported that teaching natural sciences in Arabic is a terrific experience because they can communicate with their students and achieve the objectives of their lessons more easily. They continued that their students are more willing to discuss and interact in Arabic than in French. Three instructors indicated that they feel at ease when teaching in Arabic and they thought it was the same thing for their students. They argued that Arabic "facilitates their job as teachers, and it helps their students to understand". Only one teacher reported that he enjoys teaching in Arabic just like he enjoys teaching in French.

\section{Integration and discussion of the findings}

Having presented the results of data analysis, it is now possible to discuss the findings and interpret their significance. Overall, there appeared to be a difference between AMI students and FMI ones in terms of their levels of achievement, academic selfconcept and comprehension abilities in learning scientific subjects. The analysis of data has also shown that this difference is attributed to the LOI.

\subsection{The effect of LOI on students' achievement in scientific subjects}

Results showed that AMI participants $(N=65)$ outperformed their $F M I$ counterparts with a statistically higher score $M=12.7059$ $(S D=3.18)$. This finding can be ascribed to a variety of factors, including science teachers' restricted instructional performance in French, as well as students' insufficient proficiency in the language of instruction. Rationally, poor science achievement of FMI 
groups is the result of the difficulties they encounter with science comprehension as well as their low academic self-concept. For example, $71 \%$ of them reported that French increases the difficulty of scientific subjects.

Relating these findings to previous research, it seems that they are in complete agreement with Vuyokazi (2007) who reported that there exists a positive correlation between the use of students' mother tongue (isiXhora :a native language in South Africa) and their academic achievement; similarly, Albakri (2017), in a study on the implementation of English as a medium of instruction in Oman, came to the conclusion that her participants faced great difficulties in their studies mainly because of their insufficient foreign language proficiency. Bachore (2014) elaborated on this issue asserting that "if teaching is conducted in a language students do not understand; they will be affected cognitively" (p.120).

\subsection{The effect of LOI on students' academic self-concept in scientific subjects}

As far as students' science self-concept is concerned, the findings of the study have shown that AMI students hold higher selfconcept compared to their FMI counterparts. There appears to be a consistent difference between the responses of the two groups. The mean value of the science self-concept of FMI students (2.7398) is lower than that of AMI students (4. 2615). This result may be interpreted by the fact that FMI students are disadvantaged by their low proficiency in the language of instruction which is used to teach scientific subjects.

The low level of academic self-concept of FMI students can be attributed to a variety of reasons. First, it might be assumed that the fact of not considering students' French proficiency levels when deciding the LOI of science education affects negatively their self-confidence. Second, they study in an environment imposed on them by others (the school council). Worst of all, they were not asked about which medium of instruction they preferred. Third, FMI students might be overwhelmed by the burden of thinking answers in their language and then translating them into the LOI. To put it differently, the process of learning scientific subjects becomes time and effort consuming.

These findings are in line with previous research. For example, they are in agreement with Bachore (2014) who showed the positive effects of mother tongues on students' self-concept. He discovered that students felt more comfortable and reassured by their ability to understand and analyze information in their own language. Similarly, Cummins (2000) found that students whose mother tongue is valued and used in school have a stronger sense of identity and they held higher academic selfconcept.

\subsection{The effect of LOI on students' comprehension abilities in learning scientific subjects}

Concerning students' science comprehension abilities, it must be reaffirmed that the analysis of students' responses regarding this variable showed clearly significant and consistent dissimilarities between AMI and FMI groups. Congruent with the results of academic self-concept, it has been indicated that AMI students are privileged as they possess stronger comprehension abilities in scientific subjects than their FMI peers.

Along the same lines, science teachers expressed their frustration towards the adoption of French as a LOI in science education. They admitted facing instructional difficulties when they teach scientific subjects in French although they received a few hours of training on how to teach scientific subjects in French after the implementation of the framework law of education. Among the reasons for their irritation, they mentioned that students' weak proficiency in French hampers their comprehension of scientific content. In response, teachers find themselves compelled to re-explain and, almost all the time, resort to Moroccan Arabic to explain their lessons and reduce students' frowning in confusion. This is explained by the high rate of FMI students who reported being in need of attending private lessons (63.3\%) compared to only $20 \%$ of AMI students.

The findings corroborate the research outcomes of Henderson \& wellington (1998), Merino \& Scarcella (2005), Stoffelsma \& Spooren (2019), Tina \& Wai (2007), Evelian Van, et al. (2014), and Sabri, et al. (2005) who previously demonstrated the negative effect of different second and foreign languages on students' comprehension abilities in learning scientific subjects. Sabri, et al. (2005), for example, found that the students who were taught science in English (FL) had more misconceptions than the ones who were taught in Turkish (MT). Similarly, Evelian Van, et al. (2014) reported that the students who were taught science in a language other than their mother tongue experienced difficulties with scientific subjects. In the same spirit, Alison (2011) came to the conclusion that there exists a relationship between the LOI and the child's cognitive development. Spolsky (2009) also argued that "if the teacher and student do not understand each others' speech, teaching and learning are severely impeded" (p.34).

\subsection{The effect of LOI on science teachers' instructional performance}

When it comes to the effects of the LOI on science teachers' instructional performance, the results from the interviews and classroom observations were congruent. In general terms, they revealed that teachers' instructional performance is limited when they teach their subjects in French. On the contrary, using Arabic as a medium of instruction boosts their performance. In the 
same direction, it has been found that the majority of interviewees were against the stipulation of French as a LOI, and they preferred teaching their subjects in Arabic.

Two science teachers mentioned that teaching in French is extremely tiring and time-consuming. They devote much time to translation and the repetition of their explanations because they have to teach content and language simultaneously. They received a few hours of training on how to teach scientific subjects in French after the implementation of the framework law of education. However, they admitted that they are not professionally qualified to teach science in French. This fact explains why teachers resort to Moroccan Arabic. Classroom observations revealed that teachers use pausing procedures more frequently when giving lessons in French. This practice occurred 13 times in FMI classes meaning that they encounter difficulties in formulating questions and giving instructions.

On the other hand, science teachers put forward that teaching in Arabic facilitates the teaching process. It helps them to attain the objectives of their lessons more quickly and more easily, and it enables them to communicate and interact more effectively with their students. A possible explanation for this might be the fact that their pre-service training was in Arabic. Another possible explanation is that both teachers and students have in common a good mastery of the Arabic language be it Moroccan Arabic or Standard Arabic.

In other terms, it is Crystal clear that using a foreign language as a medium of instruction does not affect only science students negatively, but also science teachers. The instructional performance of science teachers is constrained by the use of French as a medium of instruction. They suffer from insufficient proficiency in French and they tend to use a mixed code of French and Moroccan Arabic to enhance students' understanding. They looked confused and afraid of making language mistakes. They were observed focusing more on language than on the content.

This substantiates previous findings in the literature. Some studies showed that science instructors object to the use of foreign or second languages as mediums of instruction for different reasons. For example, Kilikaya (2006) and Kirkgoz (2005) found that Turkish educators opposed the use of English as a medium of instruction because it made the teaching of scientific subjects excessively time-consuming due to the amount of translation they have to do. Similarly, In Sri Lanca, Wijayatunga (2018) argued that the majority of teachers were not proficient in the medium of instruction (English). In Lebanon, Mirza (2015) examined the attitudes of math and science student-teachers towards using English as a medium of instruction. Her study revealed that teachers had to code switch from English to Arabic to ensure students' comprehension of the content.

\section{Conclusion and implications}

The primary objective of this mixed methods explanatory sequential study was to investigate the effects of the LOI on middle school students' academic self-concept, comprehension abilities and achievement in science learning, and its effect on science teachers' instructional performance. The results indicated that students' science achievement, comprehension abilities and academic self-concept are negatively affected by receiving instruction in the second language (French). The findings also indicated that science teachers' instructional performance is impeded by the adoption of French as LOI in science education. Following these findings, a number of pedagogical implications can be provided to mend for the deficiencies associated with the new language policy stipulated in the framework law of education. These include implications for middle school students, school counsellors, middle school science teachers, and finally for language policy decision-makers.

First and foremost, this study has implications for middle school students. As has been indicated by the results, FMl students are disadvantaged in science learning by the LOI. Their weak proficiency in French affected negatively their science achievement as well as their science comprehension abilities and their levels of motivation and academic self-concept. Accordingly, they are advised to think profoundly before picking a specialty in high school. Oftentimes, this choice is made on the basis of their strengths and weaknesses in the literary subjects and the scientific ones. But now, they need to consider their language proficiency levels before making a choice. Hence, the findings of this study will help them make the right choice by considering their proficiency in the languages of instruction. In brief, being good only at scientific subjects is not sufficient to follow scientific streams, the learner needs to have a sufficient proficiency level at the LOI.

The findings of this study have also an important implication for school counsellors. Due to the fact that learners' proficiency at the LOI affects their achievement in the scientific subjects, school counsellors should take this into account in the meetings they organize with students towards the end of every school year. They need to guide the learners and help them make the right choice based on their proficiency in the languages of instruction.

Equally important, this thesis offers some insights for middle school science teachers. Results showed that science instructors are not professionally qualified to teach scientific subjects in French. This disqualification might be a plausible interpretation for the challenges FMI students encounter in science learning. Thereupon, science teachers should realize their need to supplement 
their content and pedagogical knowledge with language proficiency to ensure that a smooth and successful instruction will take place in the classroom. This might also trigger collegial coordination and cooperation between French language teachers and science teachers.

Another finding of this thesis is the negative impact of FMI on teachers' instructional performance, which suggests that the recruitment of science teachers should not be based only on their content knowledge or pedagogical knowledge, but should also be founded on their linguistic competence at the LOI. The latter could be promoted for in-service teachers by providing continuous professional development programs where they can make up for their linguistic deficiencies at the LOI.

Lastly, the findings of this study have also implications for language policy decision-makers. There is general agreement among researchers that the learner should be at the heart of the teaching-learning process. Therefore, the LOI should not be imposed on learners. Instead, they need to have a say in planning for their educational careers. Accordingly, and based on the findings, it should be left to the learners themselves to decide what language of instruction they are comfortable with, and Learning Arabic and French should be promoted since elementary education. Thereupon, language policy decision-makers need to reconsider the framework law of education. One possible amendment to this law is offering science education in different languages. The variety of languages of instruction can cater for the different preferences of science learners. Moreover, in reaction to science teachers' difficulties with teaching scientific subjects in French, education officials need to provide further training that can alleviate these instructional difficulties.

\section{References}

[1] Albakri, S. (2017). Effects of English medium of instruction on students' learning experiences and quality of education in content courses in a public college in Oman. Retrieved on February $9^{\text {th }}, 2020$ from: https://ore.exeter.ac.uk/repository/bitstream/handle/10871/27743/AlbakriS.pdf?sequence=1\&isAllowed =y

[2] Alison, G. (2011). What Do Babies Think?" PsycEXTRA Dataset, 2011, doi: 10.1037/e689762011-001

[3] Bachore, M. M. (2014). Learners' success in mother tongue based classroom instruction and the attitudes and perceptions of school communities. International Journal of Sociology of Education, 3(2), 118-135.

[4] Belhassan, B. (2017). Moroccan society. Between a French dominance and English spread education as a sample. Retrieved on February $8^{\text {th }}$, 2020 from: https://www.grin.com/document/374655

[5] Belhiah \& Abilkassem. (2016). English as a Medium of Instruction in Moroccan Higher Education. Journal, Arab World English 2016, doi:10.31219/osf.io/u44p4

[6] Benmamoun, E. (2001). The Feature Structure of Functional Categories: a Comparative Study of Arabic Dialects. New York \& Oxford: Oxford University Press, 2000. Pp. Xi 180. Journal of Linguistics, 37(1), 627-649., doi: 10.1017/s0022226701221367.

[7] Cummins, J. (2000). Language, power and pedagogy: Bilingual children in the crossfire. Toronto: Multilingual Matters Ltd

[8] EL Allam \& Laaraj. (2016). Reframing Language Roles in Moroccan Higher Education: Context and Implications of the Advent of English, Arab World English Journal, December 2016.

[9] Elsworth, S. (2013). Do Language Barriers Affect Student Performance in School? Retrieved on February 17th, 2020 from: http://everydaylife.globalpost.com/languagebarriers- affect-student-performance-school-5911.html

[10] Ennaji, M. (1991). Aspects of multilingualism in the Maghreb. International Journal of the Sociology Of Language, 87(1). doi: 10.1515/ijsl.1991.87.7.

[11] Evelian, V. (2014). The Role of Students' Home Language in Science Achievement: A multilevel approach. Retrieved on March 9th, 2020, from:

https://www.researchgate.net/publication/264829458 The Role of Students' Home Language in Science Achievement A multilevel appr oach

[12] Gudula, A. (2017). The influence of language on the teaching and learning of Natural Sciences in Grade 7. Faculty of Education at the University of the Western Cape.

[13] Henderson, J., \& Wellington, J. (1998). Lowering the language barrier in learning and teaching science. School Science Review, 79 (288), pp. $35-46$.

[14] Kiliçkaya, \& Ferit. (2006). Instructors' Attitudes towards English-Medium Instruction in Turkey. Retrieved February, 11, 2020 from: https://eric.ed.gov/?id=ED570169

[15] Kırkgöz, Y. (2005). English Language Teaching in Turkey: Policy Changes and their Implementations. Retrieved on March 11th, 2020, from: https://www.academia.edu/9424296/English Language Teaching in Turkey Policy Changes and their Implementations

[16] Merino, B. \& Scarcella, R. (2005), "teaching science to English learners". Retrieved on February 3rd, 2020. From: https://escholarship.org/uc/item/26q4j33v\#page-1

[17] Mirza .S (2015). Attitudes of Math \& Science Student- Teachers towards Using English in Elementary Schools in Lebanon. Retrieved on March 25th 2020 from: https://www.academia.edu/29597461/Attitudes of Math and Science StudentTeachers towards Using English in Elementary Schools in Lebanon

[18] Mkimbili, S., \& Ødegaard, M. (2019). Student Motivation in Science Subjects in Tanzania, Including Students' Voices. Research In Science Education, 49(6), 1835-1859. doi: 10.1007/s11165-017-9677-4.

[19] Rahman, S., Mazlan, M., Kummin, S., Yasin, R., \& Meerah, T. (2010). Examining the role of language on students' achievement: a study on the use of second language as a medium of instruction in teaching science subject in Malaysia. Procedia - Social And Behavioral Sciences, 9, 1261-1265. doi: 10.1016/j.sbspro.2010.12.317. 
[20] Sabri, K, (2005). The effect of teaching in native and foreign language on students' conceptual understanding in science courses. Retrieved March 12, 2020 from: https://www.researchgate.net/publication/26453389 The effect of teaching in native and oreign language on students' conceptual understanding in science courses

[21] Sadler, Troy D. (2006) "Promoting Discourse and Argumentation in Science Teacher Education." Journal of Science Teacher Education, 17(4) 323-346., doi:10.1007/s10972-006-9025-4.

[22] Spolsky, B. (2009). Language management. Cambridge, UK: Cambridge university press.

[23] Stoffelsma, L., \& Spooren, W. (2019). The Relationship Between English Reading Proficiency and Academic Achievement of First-Year Science and Mathematics Students in a Multilingual Context. International Journal Of Science And Mathematics Education, 17(5), 905-922. doi: 10.1007/s10763-018-9905-z

[24] Tina. K \& Wai. M (2007). language development strategies for the teaching of science in English. Retrieved on March 13th, 2020 from: http://www.recsam.edu.my

[25] Vizcondes, V. (2006). Attitudes of Student Teachers towards the use of English as Language of Instruction for Science and Mathematics in the Philippines. Retrieved on March 17th, 2020 from: https://www.linguistics-journal.com/2006/11/08/attitudes-of-student-teacherstowards-the-use-of-english-as-language-of-instruction-for-science-and-mathematics-in-the-philippines/

[26] Vuyokazi, M. 2007. Science teaching and learning through the medium of English and isixhosa: a comparative study in two primary schools. Retrieved on February 24th, 2020,

from:https://www.researchgate.net/publication/228400673 science teaching and learning through the medium of english and isixhosa a comparative study in two primary schools in

[27] Wallace, S. Writing and Learning in the Science Classroom. Springer Verlag, 2007.

[28] Wenglinsky, H. (1996). Measuring Self-Concept and Relating It to Academic Achievement: Statistical Analyses of the Marsh Self-Description Questionnaire." ETS Research Report Series, 2, i-51., doi:10.1002/j.2333-8504.1996.tb01716.x.

[29] Wijayatunga. A, (2018). English as a medium of instruction in secondary schools in sri lanka: challenges. Retrieved on February 6 th, 2020, from: https://www.researchgate.net/publication/327870399 English as a medium of instruction in secondary schools in sri lanka challenges

[30] Yip, Y, \& Wing, K. T. (2006). Evaluation of the Effects of the Medium of Instruction on Science Learning of Hong Kong Secondary Students: Students' Self-Concept in Science." International Journal of Science and Mathematics Education, 5(6), 393-413., doi:10.1007/s10763-0069043-x.

[31] You, H. (2018). Assessing Science Motivation for College Students: Validation of the Science Motivation Questionnaire II Using the RaschAndrich Rating Scale Model." EURASIA Journal of Mathematics, Science and Technology Education, 14(4) doi:10.29333/ejmste/81821. 